\title{
ERRATUM
}

Ying Cao • Yutaka Fujito · Kiyoji Matsuyama

Mamoru Aoki

\section{Effects of electrical stimulation of the medullary raphe nuclei on respiratory movement in rats}

Published online: 28 February 2006

(C) Springer-Verlag 2006

\section{J Comp Physiol A (2006) Dol 10.1007/s00359-005- 0087-0}

In the Materials and methods section-Stimulation and recording - of the original publication, an incorrect value was given in the following sentence:

"Train pulse stimuli $(100 \mathrm{~Hz}, 100-200$ pulses, $20 \mu \mathrm{s}$ pulse width, $10-30 \mu \mathrm{A}$ ) were applied four to six times at intervals of $10-15 \mathrm{~s}$ in the raphe nuclei and nearby regions."
The correct sentence must read:

"Train pulse stimuli $(100 \mathrm{~Hz}, 100-200$ pulses, $200 \mu \mathrm{s}$ pulse width, 10-30 $\mu \mathrm{A}$ ) were applied four to six times at intervals of $10-15 \mathrm{~s}$ in the raphe nuclei and nearby regions."

The online version of the original article can be found at http:// dx.doi.org/10.1007/s00359-005-0087-0

Y. Cao $\cdot$ Y. Fujito $(\bowtie) \cdot$ K. Matsuyama $\cdot$ M. Aoki

Department of Physiology, Sapporo Medical University

School of Medicine, South 1, West 17, Chuo-ku,

060-8556, Sapporo, Japan

E-mail: fujito@sapmed.ac.jp

Tel.: + 81-11-6112111

Fax: + 81-11-6441020

Present address: Y. Cao

Institute of Physiology, Shandong University School of Medicine, Jinan, P. R. China 